\title{
Herbal Gold Nanoparticles for Attenuating Pandemic Infection of COVID-19 Virus
}

\author{
Nandi $\mathrm{DK}^{*}$ and Mitra $\mathrm{M}$ \\ Department of Human Physiology, Raja Narendra Lal. Khan Women's College (Autonomous), Midnapore-721102, West Bengal, India
}

\begin{abstract}
The exposure and heterogeneity of the new virus is increasing at an alarming rate. Unexpected outburst of Coronavirus has upraised various serious questions about their management using conventional diagnostic and medication measures. Vaccines help to train the immune system to avert people from developing disease, such as Covid-19. If sufficient people become immune then the coronavirus would not be able to escalate effectively. Since, there are no specific vaccines or treatment for COVID-19, so the researchers are competing to find more about it. From various review it has been found that the name "coronavirus" is derived from Latin corona, meaning "wreath" or "crown". The name point out the characteristics aspect of virions (the infective form of the virus), which possess fringe of large, bulbous surface projections producing an image reminiscent of a crown. Coronavirus are large pleomorphic spherical particles with bulbous surface projections. The average diameter of the virus particles is around $120 \mathrm{~nm}$. Infection start about when the viral spike (S) glycoprotein binds to the complementary host cell receptor. After binding, a protease of the host cell splits and activates the receptor-attached spike protein .
\end{abstract}

Keywords: Nanotechnology; Covid-19; Nanoparticle

\section{NANO-BASED ANTIVIRAL THERAPY}

Various review study proposed that coronavirus vaccine are produced by means of nanotechnology. The researchers prospered by, synthesising virus-like particles (VLPs) in the form of nanovesicles using insect cells. These nanoparticles are much similar to coronavirus, except that they do not have the virus genome; once they enter into the host's cells, they restore the immune system to fight against the infection caused by this type of virus [1-4]. Furthermore, this nanoparticles of similar sizes are capable to bind with COVID-19 viruses, and disorganize their structure with a combination of infrared light treatment. That structural disorganization would then halt the ability of the virus to survive and reproduce in the body. Development in the field of nanotechnology has embossed the necessity of utilizing therapeutic nanoparticles for the detection and treatment of diseases. Nanoparticles can damage these pathogens before they can cause any harm into the body, as they hold on to different objects and surfaces. Gold nanoparticles and carbon quantum dots (CQDs) are standout choices for interacting with the viruses and preventing their entry into cells because of their high specific surface area and possibility of being functionalized with a broad range of functional groups. These CQDs having average diameter of $10 \mathrm{~nm}$ and their good solubility in water can be ideal applicant for vanquishing against coronavirus, because they can easily enter the cell through endocytosis and interact with the virus's protein, thereby preventing viral genome replication [5]. Other nanomaterials have also been found to have effective antiviral effect. For instance, a Chinese research team has developed novel gold nanorods as a class of peptide inhibitors based, which carefully target coronavirus's S protein and retard its activity [6].

Among the metallic nanoparticles gold nanoparticles (AuNPs) has great importance because of its wider applications in biomedical, drug delivery, biosensor, antioxidant anticancer due to its biocompatibility well defined shape, size, stability and can be easily synthesized [7]. Green synthesis of herbal gold nanoparticles (AuNPs) by using plants and its extract have received much interest due to its eco-friendliness, non-toxicity, less biohazardous, cost effectiveness and easily scalable. In some research study it has been found tha AuNPs can be stabilized with certain biocompatible polymer and could act as an effective antiviral agent against HIV1, H1N1, H3N2, H5N1, bovine viral diarrhoea virus, dengue virus, and Foot- and-mouth disease virus (FMDB) [8]. For example Ahmed et al also stated that positively charged AuNPs are capable for H1N1 and H3N2 detection by mimicking peroxidase enzymatic reaction assay [9]. Various other alteration in metallic nanoparticles have been examined that could mitigate viral infection, i.e., tannic acid- modified silver nanoparticle, curcumin-modified silver nanoparticle, silver nanoparticle/chitosan composite, gallic

"Correspondence to: Dilip Kumar Nandi, Department of Human Physiology, Raja Narendra Lal. Khan Women's College(Autonomous), Midnapore-721102, West Bengal, India, Tel: +919434229882; E-mail: dilipnandi2004@yahoo.co.in

Received: May 08, 2020; Accepted: July 10, 2020; Published: July 17, 2020

Citation: Nandi DK, Mitra M (2020) Herbal Gold Nanoparticles for Attenuating Pandemic Infection of COVID-19 Virus. J Nanomed Nanotech. 11:547. doi: $10.35248 / 2157-7439.20 .11 .547$

Copyright: (C2020 Nandi DK, et al. This is an open-access article distributed under the terms of the Creative Commons Attribution License, which permits unrestricted use, distribution, and reproduction in any medium, provided the original author and source are credited. 
acid-functionalized gold nanoparticle ${ }^{13}$, and multivalent gold nanoparticles [10-12]. These virtuous metal-based nanoparticles terminate the viral infection by blocking the entry of virus to the host cell. Likewise there are several other examples where hybridized AuNPs indicateded effective antiviral activity. Hence, these findings suggest that AuNPs can attenuate pandemic infection of COVID-19 virus. Herbal gold nanoparticles has effective antiviral activity, hence further investigations are required to find out the potential beneficial effects of AuNPs to fight against COVID-19 virus.

\section{CONCLUSION}

Nanotechnology holds an immense opportunity for both viral disease diagnosis and therapeutics. From various studies it can be concluded that gold nanoparticles could be used as a measure for diagnosis and treatment of viral infections. Finally the overview of major anti-viral approaches, suggest that nano-based approaches especially AuNPs would be effective in diagnosis of COVID-19 virus for attenuating this pandemic infection across the world.

\section{REFERENCES}

1. Goldsmith CS, Tatti KM, Ksiazek TG, Rollin PE, Comer JA, Lee WW, et al. Ultrastructural characterization of SARS coronavirus. Emerg Infect Dis 2004;10(2):32026.

2. Neuman BW, Adair BD, Yoshioka C, Quispe JD, Orca G, Kuhn $\mathrm{P}$, et al. Supramolecular architecture of severe acute respiratory syndrome coronavirus revealed by electron cryomicroscopy. J Virol 2004;80(16):7918-7928.

3. Simmons G, Zmora P, Gierer S, Heurich A, Pöhlmann S. Proteolytic activation of the SARS-coronavirus spike protein: cutting enzymes at the cutting edge of antiviral research. Antivir Res 2013;100(3):605-614.
4. Alharbi KK, Al-sheikh YA. Role and implications of nano diagnostics in the changing trends of clinical diagnosis. Saudi J Biol Sci 2014;21:109-117.

5. Vijyakumar S, Ganesan S. Gold nanoparticles as an HIV entry inhibitor. Curr HIV Res 2012;10(8):643-646.

6. Ahmed SR, Kim J, Suzuki T, Lee J. Detection of influenza virus including peroxidase mimic of gold nanoparticles. Biotechnol Bioeng 2016;113(10): 2298-2303.

7. Orlowski P, Tomaszewska E, Gniadek M, Baska P, Nowakowska J, Sokolowska J, et al. Tannic acid modified silver nanoparticles show antiviral activity in herpes simplex virus type 2 infection. PLoS ONE. 2014; 9:e104113.

8. Yang XX, Li CM, Huang CZ. Curcumin modified silver nanoparticles for highly efficient inhibition of respiratory syncytial virus infection. Nanoscale. 2016; 8: 3040-3048.

9. Mori Y, Ono T, Miyahira Y, Nguyen VQ, Matsui T, Ishihara $\mathrm{M}$, et al. Antiviral activity of silver nanoparticle/chitosan composites against H1N1 influenza A virus. Nanoscale Res Lett 2013;8:93.

10. Haider A, Das S, Ojha D, Chattopadhyay D, Mukherjee A. Highly monodispersed gold nanoparticles synthesis and inhibition of herpes simplex virus infections. Mater Sci Eng C 2018;89:413-421.

11. Papp I, Sieben C, Ludwig K, Roskamp M, Bottcher C, Schlecht $\mathrm{S}$, et al. Inhibition of influenza virus infection by multivalent sialic-acid-functionalized gold nanoparticles. Small 2010; 6:2900-2906.

12. Wei JH, Zheng LT, Lv X, Bi YH, Chen WW, Zhang W, et al. Analysis of influenza virus receptor specificity using glycanfunctionalized gold nanoparticles. ACS Nano. 2014; 8:46004607. 